\title{
AS VIDEOAULAS COMO TECNOLOGIAS ACESSÓRIAS À LEITURA DE TEXTOS ACADÊMICOS: ESTUDO DE CASO A PARTIR DO CURSO DE EXTENSÃO A DISTÂNCIA PENSAMENTO LÉSBICO CONTEMPORÂNEO
}

\author{
VIDEO CLASSES AS ACCESSORY TECNOLOGIES TO READING ACADEMIC TEXTS: \\ CASE STUDY FROM THE ONLINE COURSE CONTEMPORARY LESBIAN THINKING
}

\section{CLASES EN VIDEO COMO TECNOLOGÍAS ACCESORIAS PARA LA LECTURA DE TEXTOS ACADÉMICOS: ESTUDIO DE CASO DEL CURSO DE EXTENSIÓN EN DISTANCIA PENSAMIENTO LESBIANO CONTEMPORÁNEO}

Felipe Bruno Martins Fernandes ${ }^{1}$

\begin{abstract}
RESUMO
Uma das grandes preocupações no ensino superior é a compreensão das ideias presentes nos textos acadêmicos, dimensão fundamental da educação científica. Assim, é importante que todas as etapas na leitura de um texto sejam compartilhadas entre os discentes, estimulando, dessa forma, a construção coletiva do conhecimento e promovendo um aprendizado por meio do uso da leitura e da escrita. A escrita, nesse contexto, é considerada uma habilidade e deve se tornar uma preocupação dos docentes. A aquisição dessa habilidade por parte dos discentes é o que se chama de "letramento acadêmico". A partir da reflexão sobre a construção das videoaulas do curso EAD Pensamento Lésbico Contemporâneo (UFBA, 2017), buscaremos compreender o papel das videoaulas no auxílio à compreensão de textos acadêmicos.
\end{abstract}

PALAVRAS-CHAVE: Letramento Acadêmico. Videoaulas. Educação a Distância.

\section{ABSTRACT}

One of the major concerns in higher education is student comprehension of ideas presented in academic texts as fundamental dimension of science education. Thus, it is essential that all stages in the reading of a text are shared among students to stimulate the collective construction of knowledge, and to promote learning through the usage of reading and writing. Writing, in this context, is considered a skill that should become an area of focus for teachers. The acquisition of this ability by the students is what is called "academic literacy". Drawing from our experiences teaching a Distance Learning course, entitled the Contemporary Lesbian Studies Course (UFBA, 2017), this paper offers a reflection on the role of video lessons in helping students to understand academic texts.

Submetido em: 18/12/2019 - Aceito em: 25/03/2020 - Publicado em: 29/04/2020

1 Felipe Bruno Martins Fernandes. E-mail: fernandes.felipebruno@gmail.com. ORCID: https://orcid.org/0000-0001-8755-4126. Universidade Federal da Bahia (UFBA) - Brasil. Doutor em Ciências Humanas pela Universidade Federal de Santa Catarina. Agência de fomento: Pró-Reitoria de Extensão da UFBA. 
KEYWORDS: Academic Literacy. Video Lessons. Distance Education.

\section{RESUMEN}

Una de las principales preocupaciones en la educación superior es la comprensión de las ideas presentes en los textos académicos, una dimensión fundamental de la educación científica. Por lo tanto, es esencial que todas las etapas de la lectura de un texto se compartan entre los estudiantes, estimulando así la construcción colectiva del conocimiento y promoviendo el aprendizaje mediante el uso de la lectura y la escritura. Escribir, en este contexto, se considera una habilidad y debería convertirse en una preocupación para los maestros. La adquisición de esta capacidad por parte de los estudiantes es lo que se llama "alfabetización académica". Con base en la reflexión sobre la construcción de las lecciones en video del Curso Contemporáneo de Lesbianas a Distancia (UFBA, 2017), buscaremos comprender el papel de las lecciones en video para ayudar a comprender los textos académicos.

PALABRAS CLAVE: Alfabetización académica. Lecciones en video. Educación a distancia.

\section{Introdução}

Uma das grandes preocupações no ensino superior é a compreensão das ideias presentes nos textos acadêmicos, dimensão fundamental da educação científica. Um consenso dentre o corpo docente universitário são os baixos índices de aproveitamento dos discentes quanto às ideias dos textos apresentados em aula, ou seja, há uma recorrência de reclamações dos professores de que "os alunos lêem pouco". Como sabemos, a leitura é dimensão central da aquisição de competências para uma profissão nos cursos do ensino superior e, a partir disso, buscamos compreender neste artigo como as Tecnologias da Informação e Comunicação (TIC) podem contribuir com características centrais da leitura como, por exemplo, a recepção do conteúdo, a compreensão das ideias, a capacidade de síntese e comparação de diferentes abordagens científicas que resultariam na melhoria da capacidade de escrita e no sucesso acadêmico como um todo. Assim, como as videoaulas podem ajudar a leitura de textos acadêmicos?

Quando falamos em Educação a Distância (EAD), modalidade em que há maior presença de videoaulas, somos levados, por conta da categoria "distância", ao erro. A separação física da turma, ou seja, o fato de docentes, tutores e discentes não estarem fisicamente em uma sala de aula nos momentos de ensino e aprendizagem não faz com que essa distância produza desconexão entre os sujeitos envolvidos. Segundo Manuel Castells (2000), a interação por meio de comunidades virtuais (on-line) é um fenômeno recente na sociedade mundializada. Para o autor, é necessário estudar o grau das interações estabelecido nessas comunidades para que possamos entender o impacto do mundo virtual na vida das pessoas, bem como compreender os tipos de laços que são estabelecidos e a forma como esses laços geram informações para quem interage e a forma como esses laços podem ou não se tornar fortes. Como aponta Rocha et alli (2017): 
A educação a distância pode ser entendida como uma modalidade de educação onde os participantes desse processo estão separados fisicamente no tempo-espaço, porém conectados através de meios analógicos unidirecionais que separam emissão e recepção, a exemplo do rádio, da televisão e outros meios, tais como: correspondência, DVD, vídeoaula (p. 15).

Assim, apesar do uso contínuo da categoria EAD, partimos do pressuposto da proximidade da turma, uma vez que, conectados nos modos on-line e off-line, estão articulados por meio das TIC. Com a massificação dos aparelhos com acesso à internet, todas e todos se tornaram afetados por essa cibercultura. Portanto, é possível o estabelecimento de um núcleo comum de conhecimentos em uma turma que existe exclusivamente no ambiente virtual, uma vez que as TIC, como é o caso das videoaulas, possibilitam interação de formas diversas. Dessa maneira, estamos diante de uma revolução na educação em que nossos discentes e interlocutores, mesmo aqueles com baixo capital econômico e simbólico, podem se posicionar e apresentar suas ideias e indagações com maior eficácia. As TIC têm, assim, "[...] propicia[do] a criação de novas narrativas, novas maneiras de aprender e ensinar, novos hábitos e valores, e um novo fazer cotidiano cultural e de saberes" (id., p. 17).

Segundo Ismail Xavier (2013; 2017), o vídeo nos possibilita diferentes abordagens do real. Quando produzimos videoaulas supomos que estamos simplesmente retratando uma dimensão de ensino-aprendizagem, o que não é verdade, uma vez que emular uma aula em um vídeo, possibilitando a aprendizagem, exige técnica e conhecimento sobre a tecnologia audiovisual. $\mathrm{O}$ cineasta Ismail Xavier, um engenheiro, entrou para o cinema como montador de filmes. Segundo ele, esse olhar da montagem marcou toda a sua carreira, particularmente na capacidade de perceber rapidamente relações que estão sendo estabelecidas na tela. Além disso, o cineasta afirma que não há "realidade" no filme e que essa sensação de verossimilhança que percebemos em alguns filmes ficcionais e documentários nada mais é do que a sua capacidade de "parecer real". Dessa forma, tomando as sugestões do cineasta, quando se quer alcançar a verossimilhança deve-se pensar em um enredo e em cenas que sejam capazes de ser imaginadas, ou seja, não precisamos citar literalmente a realidade para transmitir verossimilhança, uma vez que podemos usar de elementos da imagética das pessoas que conduzam a isso. Assim, para Ismail Xavier, o "efeito de real", desejado em videoaulas, é sempre resultado de uma construção por meio de determinados códigos já conhecidos pelos espectadores.

A partir dessas reflexões introdutórias buscaremos entender o papel das videoaulas no auxílio à compreensão de textos acadêmicos. Esse gênero das TIC está amplamente difundido no mundo virtual, a exemplo da rede social YouTube, na qual encontramos videoaulas sobre uma 


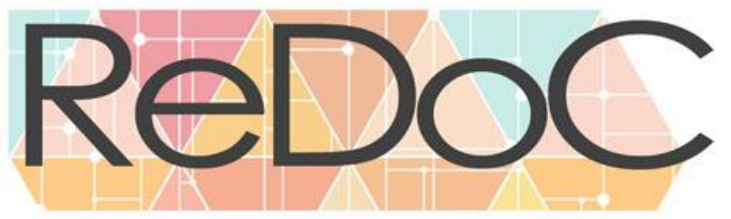

Revista Docência e Cibercultura

gama incalculável de conteúdos. Com isso, para além de advogar pela importância da incorporação das TIC no ensino superior, como objetivo específico, pretendemos contribuir com a reflexão sobre o papel destas na interpretação de textos acadêmicos, modalidade compreendida aqui como Letramento Acadêmico, a partir de um curso de extensão EAD intitulado "Pensamento Lésbico Contemporâneo", realizado pela Universidade Federal da Bahia (UFBA), com a primeira edição entre junho e dezembro de 2017 e a segunda edição entre agosto e dezembro de 2018. Prevemos ainda uma terceira edição do curso para o final de 2020.

\section{Cibercultura e Educação a Distância: que momento é esse que vivemos?}

Com o advento das TIC houve transformações importantes nas maneiras de ensinar e, consequentemente, de aprender. Essas transformações não se produzem/produziram sem conflito, uma vez que diferenças geracionais e de acesso aos bens tecnológicos incidem sobre a relação entre professores e estudantes e clivagens importantes aparecem, por exemplo, no que tange ao domínio das TIC e seu uso cotidiano, fazendo com que o corpo docente, muitas vezes, se veja em atraso em relação ao saber dos discentes. Como aponta Edméa Santos $(2011 ; 2016)$, além de promover a formação dos professores para a incorporação das TIC nos processos de ensino e aprendizagem, é fundamental que os docentes atuem na formação dos discentes para que não usem os equipamentos da cultura virtual apenas para entretenimento, mas que se tornem "autores" no mundo virtual, dimensão relacionada diretamente com o sucesso acadêmico cuja prerrogativa é a autoria.

Segundo a literatura acadêmica do campo educacional, o sucesso acadêmico é medido pela permanência dos estudantes até a conclusão do curso com condições materiais e simbólicas de aquisição das competências e capacidades da profissão para a qual está se formando (cf. SOUSA; OLIVEIRA; BORGES, 2017 e HERINGER, 2018). À vista disto, há uma dimensão política na análise do sucesso acadêmico, envolvendo recursos financeiros e materiais para que os estudantes consigam se manter na universidade em boas condições - ações afirmativas para ingresso e permanência, disponibilização de equipamentos, tais como computadores e bibliotecas, salas de estudo, sinal de internet irrestrito, residências e restaurantes universitários etc. Há também uma perspectiva pedagógica necessária com vistas a garantir que o conjunto de estudantes, em sua diversidade, compreendam os conteúdos e acessem as teorias e práticas necessárias para a aquisição dessas competências e capacidades, levando em conta as práticas culturais de seu tempo, nesse caso, o uso das tecnologias. Dessa forma, a instituição, para garantir o sucesso acadêmico dos estudantes, deve manter o corpo discente motivado para a 
conclusão do curso e para o aproveitamento dos conteúdos previstos no currículo. Como apontam Elisa Ustárroz, Sérgio Feldmann de Quadros e Marilia Costa Morosini (2017), que revisaram o conceito de "sucesso acadêmico" na literatura e documentos oficiais da área de Educação:

Partindo do princípio de que para a democratização da educação - processo integrado em um contexto geral de democratização da própria sociedade brasileira - é necessária uma busca por maior igualdade de oportunidades, acredita-se que a conclusão do curso sem interrupções é certamente um primeiro passo a ser dado integralização curricular. Não obstante, outros elementos devem ser considerados, dentre os quais: uma aprendizagem que seja reflexo de uma educação de qualidade social; um compromisso com um ensino articulado com a pesquisa e com a extensão, que satisfaça as expectativas dos estudantes, da comunidade científica e da sociedade; uma vivência acadêmica saudável do ponto de vista sócio-relacional e biopsicológico, que favoreça o desenvolvimento humano e em que as desigualdades étnicas, geográficas, de gênero, de classe, de acessibilidade e de percursos escolares não sejam obstáculos - elementos da categoria vida acadêmica. Ainda, se destacam também as questões relacionadas a uma formação sustentada em conhecimentos, habilidades e atitudes que promovam a autonomia necessária não apenas para o ingresso e permanência no mundo do trabalho e para o exercício da cidadania ativa, mas também para o desenvolvimento contínuo da própria pessoa na condição de membro de uma comunidade e o incremento de suas capacidades - cidadania (p. 557, grifos do original).

Nesse sentido, partimos da hipótese de que para alcançar o sucesso acadêmico e a democratização universitária há que se incorporar nos processos de ensino e aprendizagem nas universidades os elementos constituidores da cultura de nosso tempo, particularmente as TIC. A cultura, conceito que para a educação compreende toda produção legitimada por um grupo, faz com que a cibercultura não seja algo apartado de nossa vivência, mas a cultura de nosso tempo (SANTOS, 2011; 2016). A partir dessa visão, a cibercultura pode ser compreendida como toda produção cultural que acontece no ciberespaço.

Um dos importantes deslocamentos que produziu essa cultura do nosso tempo envolveu a passagem de um período de condicionamento para o período da mobilidade. Como analisa Edméa Santos $(2011 ; 2016)$, no início dessas transformações o nosso corpo era condicionado a um móvel, como uma mesa, e a um equipamento desktop. Quando surgiu a internet sem fio e os equipamentos móveis, como o tablet ou o smartphone, passamos a um período de mobilidade. Isso produziu um rompimento cujos resultados implicaram em uma mudança de relações. Nesse sentido, a mobilidade foi garantida pela portabilidade. Entretanto, o deslocamento não se deveu apenas ao acesso ao equipamento, uma vez que, como aponta a autora, não basta ter o suporte, é necessário também o estabelecimento de uma relação social, ou seja, toda transformação ampla necessita do outro. Por isso, a mobilidade e a inclusão cibercultural implicam o acesso ao equipamento e também a adesão às redes, ou seja, é 
necessário o trabalho em grupo para que a inclusão cibercultural exista.

Partindo desse pressuposto da cibercultura como a cultura de nosso tempo, é consenso na literatura que a incorporação das TIC em cursos presenciais, semipresenciais e a distância é o que há de mais avançado nas teorias educacionais. Entretanto, com base em nossa experiência no ensino superior, não podendo esta ser universalizada para todas as instituições acadêmicas brasileiras, o docente que inova nessa incorporação sofre resistência em diversos âmbitos da vida profissional, seja da coordenação, colegas ou discentes, comunidade esta alheia aos avanços das teorias educacionais de seu próprio tempo. Por exemplo, escutamos a todo o momento em reuniões de departamento e colegiado que o uso do tablet ou do smartphone dispersa o discente; um argumento, ao nosso ver, reacionário. Espaços como as redes sociais, a exemplo do Facebook, devem ser, como aponta Edméa Santos (2011; 2016), usados como espaços de conversação, pois diferentemente do Moodle ou de outros ambientes formais e virtuais de aprendizagem, não há a necessidade de seduzir os estudantes para aquele ciberespaço.

Por meio da compreensão dessa revolução cultural que impactou a todas e todos, novos desafios para os processos de ensino e aprendizagem foram colocados. Como já apontado, o grande problema hoje é fazer com que nossos discentes se tornem autores no ciberespaço e não apenas consumidores de conteúdos diversos. No supramencionado período do condicionamento, a internet era apenas um repositório de conteúdo. No período da mobilidade, nosso tempo, com equipamentos simples, até uma criança não alfabetizada produz conteúdo no ciberespaço, como fotos e vídeos. É nesse sentido que Edméa Santos (2011; 2016), que fundamenta essas ideias já explicitadas, define a ideia de "inclusão cibercultural" como a capacidade de autoria no ciberespaço.

Nesse contexto, a linguagem audiovisual é parte estruturante do cotidiano de todas e todos nós. Por meio do acesso ao conteúdo audiovisual, construímos não apenas nossa imagética em relação ao mundo que nos cerca, mas principalmente, nossos valores, pertencimentos e identidades. Para Nelson de Luca Pretto (2013), o vídeo é um dos componentes privilegiados da cibercultura, uma vez que "a comunicação por meio da imagem [...] possibilita a compreensão [...] dessa nova cultura que estamos afirmando estar se constituindo a partir da presença generalizada dos meios eletrônicos de comunicação" (p. 163). No que tange ao ensino superior, percebemos um grande investimento das universidades na produção de vídeos, apesar de sua eficácia ser subanalisada e sua produção passar por diferentes camadas de tensões e precarização, dado já presente na obra de Nelson de Luca Pretto (2013), que pesquisou no início dos anos 1990 o uso das tecnologias em turmas do terceiro grau de escolas públicas de quatro 
regiões do país. Assim, como podemos ver, apesar de uma tecnologia de baixo custo e altamente disseminada, seu uso no ensino superior não tem alcançado os resultados que um recurso como este deveria alcançar, já que o vídeo é majoritariamente usado como um animador de discussões do conteúdo ministrado de forma expositiva pelo docente presencialmente em sala de aula, logo, uma ferramenta acessória.

\section{O papel docente na compreensão de textos}

O processo de aprendizado das ideias presentes em um texto envolve uma série de etapas. $\mathrm{O}$ professor, preocupado com o aprendizado, deve preparar atividades que envolvam desde os momentos de pré-leitura até os momentos de leitura, compreensão e escrita sobre o que se entendeu do texto (ANGELO; MENEGASSI, 2016). Então, é fundamental que todas essas etapas sejam compartilhadas entre os discentes, estimulando, dessa forma, a construção coletiva do conhecimento e promovendo um aprendizado por meio do uso da leitura e da escrita. Com isso, evitaríamos a tendência dos discentes em afirmarem que "não gostam de escrever", ou de tornar compreensível aquilo que nossos discentes escrevem (ARAÚJO; DIEB, 2013). Vemos aqui um grande potencial para a EAD, uma vez que as atividades no Ambiente Virtual de Aprendizagem, em sua maioria, valorizam a interação entre os cursistas.

A comunicação acadêmica oral e escrita exige uma série de competências linguísticas que são pouco ensinadas no ensino superior. A escrita, nesse contexto, é considerada uma habilidade e deve se tornar uma preocupação dos docentes. A aquisição dessa habilidade por parte dos discentes é o que se chama de "letramento acadêmico". É necessário que os discentes aprendam "a produzir gêneros textuais que circulam na esfera universitária" (FERREIRA; LOUSADA, 2016, p. 126), com vistas a garantir "o desenvolvimento de estudantes universitários e pesquisadores no que diz respeito à produção textual oral e escrita na esfera universitária/acadêmica" (id., p. 136). Por isso, a produção de materiais didáticos-pedagógicos, como as videoaulas, podem contribuir para a aquisição dessa habilidade.

A partir de agora conheceremos o curso "Pensamento Lésbico Contemporâneo", apresentando a forma de construção das videoaulas e os princípios que guiaram a sua produção.

\section{O curso EAD Pensamento Lésbico Contemporâneo}

O curso EAD Pensamento Lésbico Contemporâneo foi um projeto de extensão executado pelo 
Grupo de Estudos Feministas em Política e Educação (GIRA) da Universidade Federal da Bahia (UFBA) entre os meses de junho e dezembro de 2017. Uma segunda edição, dessa vez em parceria com programas de pós-graduação da UFBA, foi realizada entre agosto e dezembro de $2018^{2}$. Teve como objetivo produzir o estado da arte do pensamento lésbico, bem como articular a UFBA com os movimentos sociais lésbicos da Bahia e de outras regiões do Brasil, estimulando a leitura de pensadoras lésbicas com vistas à construção de novas epistemologias para os feminismos contemporâneos. Beneficiou um total de 118 cursistas na primeira edição e 110 na segunda edição e contou com a adesão voluntária de 27 pesquisadoras da iniciação científica, mestrado e doutorado como produtoras de conteúdos, tutoras, mediadoras de debates e coordenadoras do curso.

O Pensamento Lésbico é uma teoria e um movimento político e cultural que emerge a partir dos anos 1970. Tem como principal eixo de análise a visibilidade da existência lésbica e a denúncia da heterossexualidade compulsória. Segundo Sam Bourcier, o movimento se potencializou com o feminismo de segunda onda e sua reivindicação pelo direito ao corpo e ao prazer e também com o movimento de libertação LGBT e a defesa do direito à livre orientação sexual (COSTA et al., 2015).

No campo teórico, os principais conceitos do Pensamento Lésbico são os de "existência lésbica" e "heterossexualidade compulsória" (RICH, 2010). A partir deles, a heterossexualidade é uma instituição política que retira o poder das mulheres, o que faz com que a existência lésbica sofra um processo de apagamento social. Já Jules Falquet (2012) aponta o aprofundamento vertiginoso das desigualdades de classe, raça, gênero e sexualidade imposto pelo neoliberalismo, exigindo o resgate das premissas feministas formuladas nos anos 1970 de liberdade sexual e de combate ao capitalismo para promover a lesbianidade enquanto um posicionamento crítico capaz de oferecer tecnologias sociais para a transformação social mais ampla.

O curso foi realizado exclusivamente na plataforma Moodle da UFBA em que, semanalmente, foram apresentadas duas autoras do pensamento lésbico. A apresentação se deu por meio de dois recursos didáticos: as videoaulas e os textos das autoras em formato PDF. Em dois casos foram disponibilizados áudios gravados de conferências de autoras e entrevistas realizadas. Para cada autora foi aberto um Fórum de Discussão em que as cursistas deveriam apresentar as ideias centrais das autoras, tecer relações entre as autoras e entre o pensamento apresentado e suas experiências de vida, além de interagir com outras cursistas. Ao final de cada curso, as cursistas concluintes elaboraram um texto teórico de até oito páginas. Os textos da primeira

\footnotetext{
${ }^{2}$ Uma terceira edição, com muitas alterações no formato e estratégias pedagógicas a partir dos aprendizados que tivemos nas duas primeiras edições, está prevista para os meses finais de 2020.
} 
edição do curso serão publicados em formato $e$-book e os melhores textos da segunda edição serão publicados em dossiê sobre o tema em periódico nacional da área de estudos da homocultura.

As autoras do pensamento lésbico trabalhadas no curso foram: Adrienne Rich, Audre Lorde, Cherríe Moraga, Cheryl Clarke, Dorotea Gómez Grijalva, Fatima El-Tayeb, Gayle Rubin, Gloria Anzaldúa, Jasbir Puar, Judith Butler, Jules Falquet, Maria Luiza Heilborn, Miriam Pillar Grossi, Monique Wittig, Ochy Curiel, Paola Bacchetta, Sam Bourcier, Sokari Ekine, Tania Navarro Swain, Tanya Saunders e Yuderkys Espinosa Miñoso. A maioria delas são pesquisadoras das Humanidades, prevalecendo os campos da História, Antropologia, Sociologia, mas também das Artes, particularmente Comunicação, Teatro e Literatura. Dessa forma, a perspectiva do curso foi interdisciplinar (FERNANDES; CARLOS, 2009), ou seja, privilegiou o encontro entre diferentes disciplinas na constituição de um novo paradigma científico, o Pensamento Lésbico.

Nesse momento, objetivamos apresentar os princípios que guiaram a construção das videoaulas, partindo do pressuposto de que se tratam de tecnologias fundamentais de suporte à leitura de textos complexos, oferecendo às cursistas chaves interpretativas para a compreensão do pensamento das autoras.

As videoaulas consistiram em vídeos curtos de, no máximo, oito minutos. Foram convidadas pesquisadoras mestrandas e doutorandas para a elaboração dos textos-base de cada videoaula, que foram produzidas a partir de um software de apresentação de slides (Keynote). Nesse sentido, apenas duas videoaulas, a introdutória do curso e aquela sobre o pensamento de Monique Wittig, apresentaram vídeos com docentes dissertando sobre o tema. Na videoaula introdutória, em que foram apresentados os princípios e a proposta de dinâmica do curso, no minuto inicial, uma das coordenadoras deu boas vindas às cursistas. Na aula sobre Monique Wittig apresentamos uma entrevista com a antropóloga Miriam Pillar Grossi sobre a importância do pensamento da autora. Em todas as outras videoaulas, o modelo consistia de uma apresentação de slides com legendas, áudio gravado e imagens em formato JPEG ou GIF que ilustravam as ideias apresentadas. Na aula sobre o pensamento de Tanya Saunders também foi usada a tecnologia do podcast.

Todas as videoaulas foram construídas em cima de um template pré-elaborado em formato de 1920x1080 pixels, recomendado para a plataforma YouTube, em que os vídeos foram difundidos e, posteriormente, incorporados no Moodle. O template possuía fundo roxo escuro, uma vez que essa é a cor representativa do feminismo. As videoaulas eram precedidas por uma animação que trazia a identidade visual do curso e procedidas pelos créditos finais do projeto 
e da aula específica. As legendas foram apresentadas na cor branca com sombra preta e receberam o efeito "Máquina de Escrever", ou seja, os caracteres apareciam sincronizados com o áudio, algo que tomou muito tempo para a construção. Foi usado o efeito cross dissolve entre as telas. Uma música de fundo com direitos autorais abertos, Always, do $\mathrm{Dj}$ Quads, disponibilizada gratuitamente para uso no YouTube, foi incluída em todas as videoaulas, juntamente com os áudios gravados. Dessa forma, cada videoaula seguiu o mesmo modelo, garantindo não apenas a identidade visual do curso, mas a facilidade na edição, uma vez que, com o template pronto, bastou adequá-lo para cada temática.

Antes da produção do template das videoaulas, um vídeo-piloto foi elaborado sobre o pensamento da antropóloga Cláudia Fonseca. Para essa videoaula foi escrito um texto de uma lauda, que iniciava com uma pergunta que, do ponto de vista pedagógico, dava conta do conteúdo a ser apresentado no curso. Esse primeiro texto foi enviado às diferentes colaboradoras, que construíram, então, textos específicos para cada autora. Esse texto, após a edição e correção/adequação do conteúdo, era replicado no template, sendo que cada frase se tornava uma tela. Uma das integrantes da equipe era então convidada para gravar o áudio. A gravação de áudio gerava um arquivo individual para cada tela que, após inserido, era sincronizado com a legenda, garantindo que o mesmo tempo gasto no áudio seria gasto na legenda. Com a voluntária que gravava o áudio eram definidas imagens da internet que ilustravam aquela tela. Após a gravação e edição de todas as telas, o vídeo era exportado em formato MOV e postado no YouTube, criando-se uma playlist com todas as videoaulas. Percebemos que a maior parte da interação com o vídeo, uma vez que foram disponibilizados na categoria "não listado" no YouTube, aconteceu no Moodle da UFBA, com pouquíssima interação na rede social (Figura 1). 


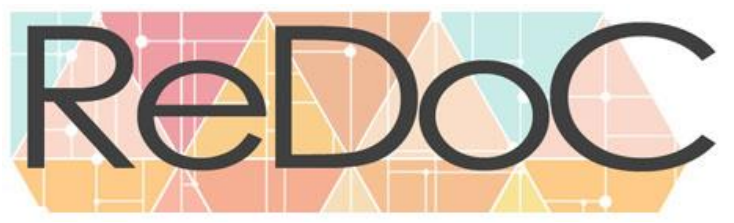

Revista Docência e Cibercultura

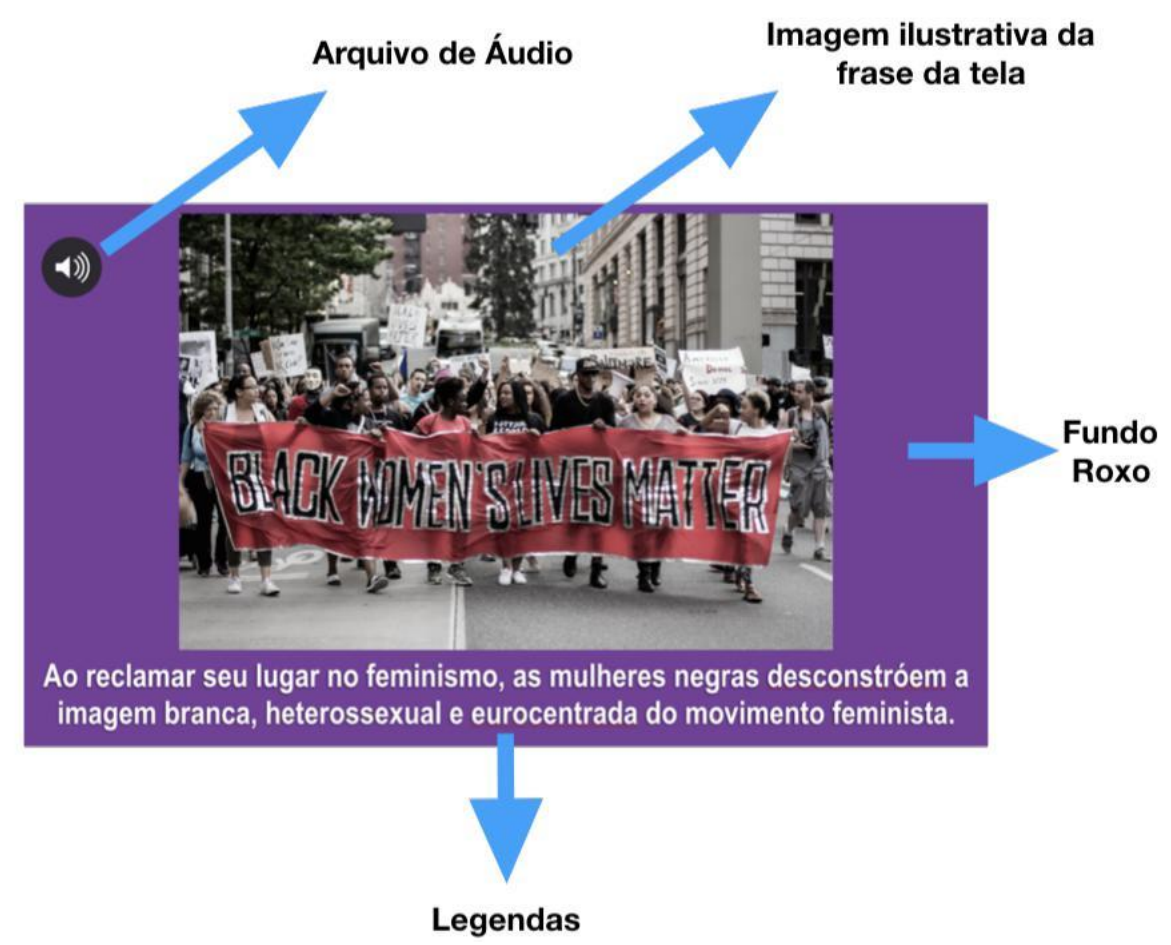

Figura 1. Exemplo de tela de videoaula do curso Pensamento Lésbico Contemporâneo Fonte: Elaboração própria.

Na dinâmica de construção das videoaulas, buscamos garantir que o conteúdo apresentado refletisse uma síntese do pensamento da autora, incluindo não apenas as ideias centrais, mas as evidências que contribuíram na definição daquele pensamento. Assim, pudemos alcançar o objetivo de qualificar a leitura daquelas autoras, uma vez que, antes de ler o texto, as cursistas tiveram acesso a essa síntese, mediando a leitura com chaves interpretativas já apresentadas pela equipe de coordenação do curso (Apêndice A).

Como o curso era composto não apenas de pesquisadoras, mas também de ativistas dos movimentos sociais, os vídeos possibilitaram que mesmo aquelas pessoas com menor prática de leitura de textos acadêmicos tivessem acesso ao pensamento de feministas intelectuais e percebemos que o vídeo estimulou a leitura, e não o contrário. A maioria das cursistas elogiou o método apresentado (videoaulas, textos e fóruns), entretanto, duas delas - como veremos no próximo tópico, que analisa especificamente as postagens de algumas cursistas - demonstraram dificuldades de foco com base na produção dos vídeos com imagens, áudio e legendas. Ao final do curso, foi organizada uma jornada presencial com a participação de pesquisadoras lésbicas de várias universidades federais do país. 


\section{As posições das cursistas sobre o papel das videoaulas como tecnologias acessórias à leitura de textos acadêmicos}

Passamos nesse momento a trazer trechos dos fóruns do curso para entendermos o papel das videoaulas na compreensão dos argumentos e ideias dos textos, bem como nas maneiras que impactaram as cursistas dos pontos de vista subjetivo, político e profissional, além de concluir com as críticas apresentadas pelas cursistas ao material elaborado pela equipe do curso.

Um dos primeiros aspectos que nos chamou a atenção nos fóruns do curso foi o papel das videoaulas como uma tecnologia acessória na compreensão dos textos propostos, muitas vezes complexos e cheios de conceitos e discussões em linguagem acadêmica elaborada e de difícil compreensão para o público desacostumado com esse tipo de leitura, mesmo sendo a maioria de nossas cursistas estudantes universitárias ou graduadas. Dessa forma, percebemos nas falas das cursistas a importância do estudo associado do vídeo e do texto:

Uma outra questão que já vinha pensando, mas que retornou quando li os textos e assisti os vídeos é que quando falamos sobre uma coisa, necessariamente deixamos de falar de outra. Creio que entender isso profundamente é um grande ganho político (Mulher cisgênero, lésbica, branca, 23 anos, estudante universitária).

Depois de ter assistido a videoaula e lido os textos escolhidos de Audre Lorde, realmente não dá para passar sem ser tocada por eles e pensar as várias perspectivas sobre as várias questões que ela aborda, mas que tem a liberdade, o direito de ser, amar, existir, lutar, resistir como forças e bases (Mulher cisgênero, lésbica, negra, 29 anos, filósofa).

A leitura do texto e a videoaula acerca do pensamento de Miriam Grossi me fez refletir sobre o processo de entendimento da subjetividade para compreender como as relações sociais são construídas e como isso impacta na nossa identidade (Mulher cisgênero, lésbica, negra, sem registro de idade, cientista social).

Como mostra a videoaula e podemos ler no (maravilhoso) Lesbianismo: um ato de resistência, Cheryl Clarke apresenta reflexões e proposições radicais acerca de vários temas (Mulher cisgênero, lésbica, branca, 24 anos, estudante universitária).

Vemos nessas postagens que a prática de estudos no curso, desenvolvida ao longo do processo, se deu através da leitura do texto associada à videoaula e que as cursistas acessaram ambos os materiais didáticos ao mesmo tempo, buscando densificar seus entendimentos das ideias das autoras. Além disso, vemos nas postagens abaixo que as videoaulas também auxiliaram a compreensão pós-leitura dos textos, trazendo chaves interpretativas para as cursistas entenderem argumentos complexos, inclusive aqueles que no próprio texto não foram devidamente densificados: 
No texto proposto para leitura, a autora não desenvolve o termo 'heteronação', embora disserte a respeito dos mecanismos que levam à construção do conceito dentro de nossas vivências políticas e sociais. Pelo que pude depreender do vídeo, a heteronação, sustentada no conceito de 'antropologia da dominação', é uma organização política determinada pela heterossexualidade/heteronormatividade, fomentada por mecanismos de poder de instituições políticas, jurídicas, religiosas e mesmo sanitárias, que definiriam não só as bases de uma determinada nação, mas influiriam em nossas vivências, discursos, experiências (Mulher cisgênero, lésbica, negra, 28 anos, letróloga).

Só pude ler [o texto] hoje e elucidou algumas das minhas percepções ao ver o vídeo, realmente eu estava me referindo mais à videoaula do que ao texto. Estou sem tempo de elaborar mais agora, mas pensando sobre tudo que li! (Mulher cisgênero, lésbica, branca, 24 anos, estudante universitária).

Ademais, percebemos que algumas cursistas interagiram nos fóruns exclusivamente a partir das videoaulas, tendo sido estas um mediador importante nas discussões para aquelas que, em caráter extraordinário, não puderam ler os textos. Também as videoaulas cumpriram importante papel na sedução das cursistas para a leitura dos textos, tendo funcionado, em outro momento, como uma barreira na produção de desejo de leitura:

Bem, depois de assistir a videoaula e ver os principais conceitos e preocupações do autor, confesso que não fiquei nada empolgada em ler a entrevista. Mas me surpreendi, não com seu pensamento, que continuo achando fraco e liberal, mas com suas críticas às produções feministas das mais diversas (Mulher cisgênero, lésbica, negra, 23 anos, estudante universitária).

A partir do vídeo, o que me parece mais interessante para pensar a autora é a ideia de que 'a dominação cria a diferença; e não a diferença que cria a exclusão'. Dessa forma, as mulheres e as lésbicas são consideradas como o 'Outro', tanto ao que se refere aos imaginários quanto à ideia de nação (Mulher cisgênero, sem registro de orientação sexual, branca, 29 anos, cientista social).

Quanto ao vídeo, achei elucidativo e valioso, pois o pensamento de Miriam [Grossi] a respeito da subjetividade pode funcionar como bom fundamento teórico em uma tese, por exemplo, para estudos de gênero e como estes impactam na coletividade (Mulher cisgênero, lésbica, branca, 26 anos, doutoranda).

O que fica pra mim do pensamento de Cherríe Moraga é a importância de unir as especificidades na militância, como traz no vídeo: 'um dos maiores problemas do feminismo é a negação das diferenças' (Mulher cisgênero, não heterossexual, branca, 22 anos, estudante universitária).

Na videoaula da [Jules] Falquet, essa posição na divisão sexual do trabalho também aparece - na amalgamagem - e é uma questão que me interessa muito. Essa ideia de que ser mulher não está só associado aos papéis e comportamentos esperados de nós, mas a um trabalho que somos obrigadas a realizar, essencial para a manutenção da sociedade, mas tratado como um 'instinto natural', o trabalho reprodutivo (Mulher cisgênero, lésbica, amarela, 25 anos, estudante universitária). 


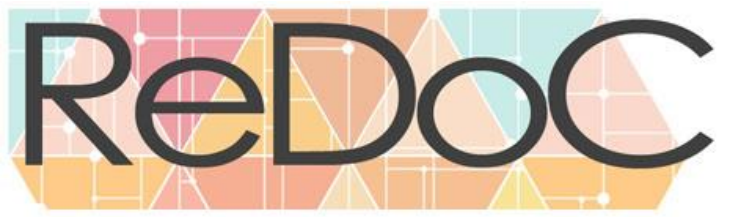

Revista Docência e Cibercultura

Partindo de uma perspectiva mais didática, também percebemos que o vídeo atuou fortemente como um disparador de discussões nos fóruns, direcionando em certa medida os debates e promovendo o chamamento das cursistas para a discussão:

Creio ser fundamental considerar o que o vídeo e a entrevista trazem sob as próprias palavras do autor, que se coloca em lugar de reconhecido (por si mesmo, inclusive) privilégio europeu, branco e de uma série de ordens que ele mesmo expõe em suas reflexões. A videoaula, ao final, traz destaque para o feminismo em Sam [Bourcier] $e$ como este 'pautou, durante muito tempo, sua ação política pelo paradigma da violência' e reitera a análise do autor em questão que diz, algumas vezes (inclusive na entrevista disponibilizada para estudo), que o papel do feminismo é também de 'retomar o projeto inicial de liberdade sexual e valorização das subculturas sexuais e de gênero'. Porém, dentro de nossa vivência como lésbicas numa América sub e precarizada, objetificadas e violadas, como considerar o apagamento inerente da identidade lesbiana postulada por suas teorias? (Mulher cisgênero, lésbica, branca, 28 anos, mestranda).

No início da nossa videoaula coloca-se uma pergunta norteadora: 'qual o lugar da subjetividade na produção do conhecimento e ação política?'. Creio que este enunciado vai ao encontro do que quero propor pensarmos aqui sobre a dicotomia sujeito x objeto (Mulher cisgênero, sapatão, não branca, 24 anos, historiadora).

Mas como atestado acima, essa não foi uma regra, tendo a articulação entre a videoaula e o texto prevalecido na dinâmica de estudos das cursistas:

O próprio título do vídeo e o primeiro parágrafo do texto colocam o lesbianismo como 'a radicalização extrema na recusa de um mundo patriarcal, propondo o separatismo na vida social, a criação de espaços de onde os valores masculinos seriam extirpados' (Mulher cisgênero, lésbica, branca, 23 anos, estudante universitária).

Eu gostei muito do vídeo da [Cherrie] Moraga e do comentário [...]. Ele me fez lembrar muito do trabalho da boliviana Maria Galindo, que pensa o corpo como território político e afirma que ao pensarmos em despatriarcalizar, precisamos pensar em descolonizar, um não pode andar sem o outro, já que a colonialidade ainda reflete em nossa identidade e forma de pensar o mundo, que acredito que seja o mesmo que Moraga propõe (Mulher cisgênero, lésbica, branca, 27 anos, estudante universitária).

Outra questão relevante para o argumento do papel das videoaulas na compreensão das ideias presentes nos textos diz respeito à tecnologia como suporte de estudo e sucesso acadêmico, em que o vídeo pode ser compreendido como tecnologia de nivelamento dos entendimentos de toda a turma, composta de trajetórias diversas, das ideias das autoras:

Os textos de Audre Lorde são repletos de vigor e beleza. Indicam caminhos por que percorrer na luta por uma sociedade mais equivalente. Em Não há hierarquia de opressão, como explica a videoaula, se eu entendi bem, a autora avança no que depois viria a embasar o conceito de interseccionalidade, assumindo que uma identidade 
perpassa diferentes identidades importantes (Mulher cisgênero, lésbica, branca, 25 anos, estudante universitária).

O contato com o pensamento da autora me possibilitou refletir sobre algumas questões, especialmente depois da diretriz colocada na videoaula: o papel da subjetividade nas ações políticas diárias (Mulher cisgênero, lésbica, branca, 25 anos, estudante universitária).

Quanto ao vídeo: Transformando o pessoal em coletivo[, aprendemos que] a experiência é sempre subjetiva e é importante transformar o pessoal em coletivo para permitir o conhecimento da individualidade por diferentes pessoas (Mulher cisgênero, lésbica, branca, 36 anos, bióloga).

A partir da apresentação na videoaula e dos textos da antropóloga Miriam Grossi, percebe-se de maneira muito forte como os debates sobre feminismo e lesbianidades são fundamentais para o rompimento de diversos tipos de preconceito e obtenção de conhecimento aprofundado sobre o assunto (Mulher cisgênero, lésbica, branca, 23 anos, relações públicas).

Isto posto, ao entendermos os Estudos Lésbicos como um campo permeado por subjetividades, particularmente das autoras, mas também das leitoras, o vídeo auxiliou na compreensão da autoria como dimensão que parte de um ponto de vista, valorizando, nesse campo científico dos Estudos de Gênero, as trajetórias das pesquisadoras que escrevem sobre o tema das lesbianidades:

O vídeo e os textos da autora foram excelentes para a primeira semana de curso. Apresent[aram] de variadas formas a importância de 'transformar o que é pessoal em coletivo, social, histórico'. Admirável a trajetória da autora. Nos faz acreditar que é, sim, possível transcender (Mulher cisgênero, bissexual, parda, 42 anos, pedagoga).

Nas discussões propostas pelas cursistas que postaram suas interpretações $e$ avaliações neste fórum, fica claro a problemática do sujeito no campo da pesquisa e a importância da sua emergência nos estudos antropológicos e, sobretudo, em um tempo histórico de questionamento das naturalizações socialmente postas. Essa perspectiva foi, inclusive, o ponto de partida do vídeo, enriquecido com a sua biografia para conseguirmos alinhar sua corrente de pensamento à sua experiência como sujeito da própria pesquisa (Mulher cisgênero, lésbica, negra, 31 anos, historiadora).

Outro dado relevante sobre o uso do audiovisual pelas cursistas foi a utilização que fizeram da tecnologia como uma matriz comparativa entre o pensamento de diferentes autoras:

Esse saber localizado na história, que respeita e incentiva as multiplicidades de ser e estar no mundo, é extremamente necessário para pensarmos em uma emancipação das pessoas. $O$ texto e o vídeo deixam claro: são muitos sistemas de opressão que trabalham juntos, e não adianta focar apenas em um, acreditando que está suficiente. Esses sistemas terão que ser modificados em conjunto para que uma mudança satisfatória ocorra. Isso me fez lembrar de [Jasbir] Puar e do homonacionalismo, 
porque o exemplo do vídeo de [Fatima] El-Tayeb fala sobre o casamento igualitário. Essa é a prova cabal de como as coisas funcionam: um Estado que se vangloria de ser bom para os LGBTs, mas é racista e xenofóbico (Mulher cisgênero, bissexual, branca, 23 anos, psicóloga).

Nessa perspectiva de interconexão entre diferentes produtos audiovisuais, em uma das aulas do curso propusemos a análise de uma autora em paralelo com um videoclipe da música "Um corpo no mundo", de Luedji Luna. Nesse sentido, videoclipe e videoaula trabalharam juntos na contribuição à compreensão dos argumentos do texto para leitura, conforme atestado por duas cursistas:

Para mim, o trecho da música fala sobre uma pessoa que sai de um lugar e vai para outro, trazendo, é claro, não só seu corpo, marcado pela cultura em que vive, mas as vivências da pessoa em questão. Acho que pode ser feito um paralelo entre tal trecho e o texto/vídeo, no qual verificamos que, muitas vezes, nosso corpo elou vivências parecem não corresponder ao lugar em que estamos, ou ao que vemos nas agendas LGBTs (Mulher cisgênero, lésbica, negra, 27 anos, doutoranda).

Sobre o vídeo da autora Fatima El-Tayeb e a música 'Um corpo no mundo', relato que tenho aprendido a entender a importância do meu corpo no mundo e buscado 'atravessar o mar', com plena convicção de que 'eu sou minha própria embarcação' (Mulher cisgênero, bissexual, parda, 42 anos, pedagoga).

Essa interconexão supramencionada também emergiu no curso por meio do diálogo com outros produtos audiovisuais, dessa vez propostos pelas próprias cursistas:

Hoje assisti um vídeo sobre LGBTs na periferia e eles falam de como as pessoas LGBTs se dividem (de classe média alta e os de periferia) e como a opressão é grande nesses lugares, muito interessante! Acho que por isso é importante os movimentos não discutirem apenas na universidade, olhar também para a busca da saída de espaços privilegiados (Mulher cisgênero, lésbica, branca, 24 anos, estudante universitária).

Nessa busca por produtos audiovisuais que contribuíssem com a compreensão do pensamento das autoras, percebemos também a busca por entrevistas e textos não acadêmicos das autoras como formas de auxiliar na compreensão dos argumentos e ideias dos textos:

Gostei muito da sua colocação. De fato, para mim é bem difícil ler esse texto da [Judith] Butler. A linguagem e as referências tornam essa tarefa bem complicada e já vou seguir sua dica de buscar vídeos de entrevistas dela etc. (Mulher cisgênero, bissexual, branca, 23 anos, psicóloga).

No que tange a uma construção subjetiva e política das cursistas por meio do estudo do pensamento das autoras nos textos e videoaulas, muitas discussões emergiram sobre a posição social das autoras e das cursistas, um evidente impacto das teorias da interseccionalidade nos Estudos de Gênero no Brasil. Conforme vemos no relato abaixo, além da circulação de uma 


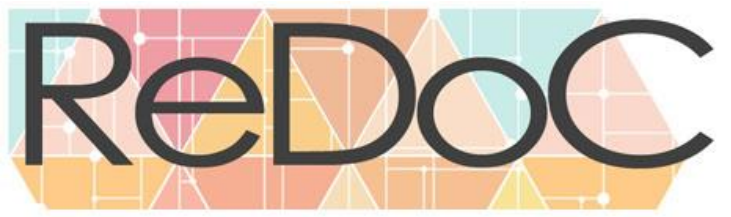

Revista Docência e Cibercultura

ideia freireana de "unidade na diversidade", houve um elogio da acessibilidade das videoaulas, principalmente pela presença de legendas que possibilitaram a inclusão dessa cursista surda:

\begin{abstract}
Mesmo com atraso, queria tecer um breve comentário sobre o que eu entendi da perspectiva dela sobre conviver com os diferentes. Ela na verdade não está desqualificando a convivência 'entre iguais', mas que em determinados contextos o 'juntos e misturados' também traz potência, faz diferença para justamente não excluirmos o outro, não produzirmos apagamentos identitários. Eu sou branca e se não fosse a minha convivência com algumas pessoas negras na minha trajetória acadêmica, eu não teria toda a convicção teórica e subjetiva da importância do enfrentamento ao racismo, mesmo o racismo institucional. Eu entendi que não basta apenas ser contra o racismo, é preciso também ser antirracista. Entender que é importante confrontar meu pensamento antirracista para meus 'pares brancos' racistas, já que o racismo de muitos, muitas vezes acaba por desqualificar as palavras e lutas antirracistas das pessoas negras. Mas eu sou uma branca que, por acaso, também é surda. E lésbica. Se não fosse a convivência de meus colegas comigo, tenho absoluta certeza que eu não estaria nem aqui interagindo com vocês, pois foi através da convivência do prof. Felipe comigo que ele entendeu a importância de acessibilizar as videoaulas para que eu pudesse ter acesso à comunicação e informação. Enfim, o que quero dizer com isso é que, já que o curso é sobre pensamento lésbico, lesbianizar as interseccionalidades é preciso. No meu caso, lesbianizar a surdez. Mas pode ser tantas outras diferenças. E como se faz isso? O primeiro passo certamente é aprendermos a conviver com todas as diferenças, 'hegemônicas' e 'não hegemônicas'. E, claro, também termos nossos momentos de individualidade quando precisamos conviver 'entre pares', não é mesmo? (Mulher cisgênero, lésbica, branca, 42 anos, doutoranda).
\end{abstract}

Com base no trecho acima, percebemos que as videoaulas auxiliaram as cursistas a produzirem coletivamente transformações subjetivas importantes, que as fizeram repensar sobre seus próprios lugares nessa sociedade:

Acho que, para além do prazer que as pessoas podem sentir ao ver os vídeos, é interessante pensar na reflexão entre as práticas que vemos nos vídeos e nossas próprias práticas, e, como você mesma falou, é possível descobrir coisas que podem ser úteis, inclusive, pensando na nossa saúde sexual (mas não só) (Mulher cisgênero, lésbica, negra, 27 anos, doutoranda).

Após a leitura dos textos indicados e de assistir o vídeo-resumo, eu escolhi destacar três aspectos que me chamaram a atenção durante os estudos. Em primeiro lugar, não sou exatamente uma estudiosa das questões de gênero, isto é, não chego a esse debate por uma necessidade acadêmica. Meus estudos sobre gênero e feminismo são uma consequência da minha prática militante e da necessidade de amadurecê-la. É preciso deixar claro que o meu caminho é somente um entre tantos, e nem por isso mais ou menos importante. Faço essa observação sobre mim, pois fiquei bastante feliz em ler sobre a vida de Miriam [Grossi] e descobrir que seu percurso de pesquisa sempre perpassou pelos caminhos de sua própria militância. Acredito que todo fazer acadêmico é político, e encarar a pesquisa dessa forma é primordial para extrapolarmos os muros das universidades e centros de pesquisas (Mulher cisgênero, lésbica, parda, 30 anos, historiadora). 
Nessa construção subjetiva durante as aulas semanais do curso, percebemos que as videoaulas associadas à leitura dos textos contribuíram para o posicionamento político das cursistas, que atribuíram ao vídeo deslocamentos importantes em suas visões posições diante da sociedade:

Em relação ao que é falado no vídeo sobre a análise da autora sobre a Constituição, não é novidade que as leis são criadas por e para homens brancos, héteros e de classe alta (Mulher cisgênero, lésbica, branca, 23 anos, biomédica).

O vídeo sobre a ativista lésbica negra nos elucida quanto à luta por uma legislação que acaba por favorecer somente uma parte da população LGBT, mas para fazer com que o movimento se articule pensando no coletivo diverso que abarca, é necessário visibilizar. O movimento precisa urgentemente visibilizar mulheres, visibilizar pessoas negras, para não ter um fim nele mesmo (Não binária, sapatão, negra, 27 anos, produtora cultural).

Além da atuação política e da subjetividade, aprendemos durante o curso que a tecnologia do vídeo já integra a prática profissional de algumas delas, já docentes tanto na educação básica como no ensino superior:

Em cursos de pós-graduação, a exemplo da Especialização em Alfabetização e Gestão Escolar, enquanto facilitadora de uma disciplina, dentre diversos recursos, utilizo vídeos e fotos das minhas intervenções performáticas drag king em um dos blocos de debates e reflexões trazendo à tona questões do cotidiano daquelas/es profissionais (Mulher cisgênero, lésbica, negra, sem registro de idade, pedagoga).

Por fim, apesar de posições minoritárias no curso, cabe trazer as críticas das cursistas ao material audiovisual elaborado. Uma primeira crítica, que apontamos abaixo, diz respeito à videoaula como redutora do pensamento da autora estudada:

O livro da Tânia Navarro [Swain], O que é lesbianismo, e muitos de seus artigos publicados na revista Labrys fazem parte do meu arcabouço de feminismo lésbico e me são muito caros. Especificamente no livro encontro algumas das contradições que vi na videoaula, o conceito de patriarcado e toda elaboração da história $e$ invisibilidade forçada das lésbicas leva a uma compreensão de que devemos afirmar nossa existência, mas aí, se depois são adotados conceitos posteriores, como de binarismo de gênero, identidade nômade, dá-se a volta e chegamos novamente num esvaziamento do ser lésbica. Isso ocorre no livro e, nessa videoaula, por ser muito mais curta e em outro formato, fica gritante (Mulher cisgênero, lésbica, branca, 24 anos, estudante universitária).

Além dessa crítica de redução, algumas cursistas também levantaram que a interpretação de quem escreveu o conteúdo das videoaulas destoava da interpretação que elas próprias tiveram do pensamento das autoras, possibilitando, dessa maneira, interessantes debates nos fóruns do curso:

Olá pessoas, a impressão que tive ao ter contato com o estudo da autora no texto sobre identidade de gênero, depois de saber sua trajetória na entrevista publicada, 
foi bem diferente da que tive ao ver o vídeo (Não binária, sapatão, negra, 27 anos, produtora cultural).

No vídeo vocês usaram o termo 'patriarcado negro', o que pode ser facilmente compreendido como a violência do homem negro com a mulher negra, porém, é um termo socialmente perigoso, pois fala-se de um patriarcado essencialmente negro e nossa história e construção cultural é outra. O que [Cheryl] Clarke levanta no texto é a violência da comunidade negra com as mulheres lésbicas, e especificamente do homem negro com a mulher lésbica (Não binária, sapatão, negra, 27 anos, produtora cultural).

Também, conforme a postagem abaixo, para as cursistas algumas discussões centrais no pensamento das autoras acabaram ficando de fora das videoaulas, mesmo estas tendo a pretensão de resumir o pensamento e propor chaves interpretativas dos textos:

Foi o primeiro texto sobre heterossexualidade compulsória que li na vida, em 2014, e abriu minha cabeça pra várias questões! Porém, de resto, nem me sinto à vontade lendo texto quando ele, na videoaula, é apresentado como sendo sem recorte de raça e gênero (Mulher cisgênero, lésbica, branca, 27 anos, estudante universitária).

Finalmente, duas cursistas apontaram o formato das videoaulas, com imagens, áudio e texto, como confusos, por isso, de difícil apreensão das ideias. Ambas, conforme abaixo, apontaram que o formato deveria ser outro, menos confuso e que a leitura dos textos sem a tecnologia das videoaulas se mostrou mais eficaz para seus estudos:

Compreendo que o material já esteja pronto e que a esta altura seja difícil modificálo. Não quero gerar trabalho extra para os voluntários e monitores que devem estar bem atarefados com todo o curso. Só disponibilizar os textos das videoaulas [transcrição do áudio] acho que já ajuda. Eu assisto os vídeos pausando caso tenha alguma parte que a visualização do conteúdo seja essencial para a compreensão do material. Realmente, não sei qual é o procedimento padrão para a construção desse tipo de material, mas percebo que sempre encontro dificuldade com materiais com essas características (Mulher cisgênero, lésbica, branca, 32 anos, historiadora).

Mesmo tento lido as respostas às observações feitas pela colega, gostaria de também deixar registrada a minha dificuldade quanto à absorção no conteúdo das videoaulas. As imagens tiraram constantemente o meu foco, fazendo com que o vídeo sempre precisasse ser pausado para a releitura do conteúdo apresentado. Acredito que a disponibilização dos textos apresentados em vídeo em PDF seria de grande ajuda, enquanto isso, seguirei ouvindo apenas os áudios (Mulher cisgênero, lésbica, branca, 21 anos, estudante universitária).

Nesse tópico pudemos ver, a partir de excertos de postagens de cursistas nos fóruns, que as videoaulas foram parte integrante da dinâmica de estudos em um curso EAD. Para mais, foram importantes tecnologias que as auxiliaram na compreensão das ideias dos textos, além de terem participado ativamente como propulsoras de discussões no Moodle. Enfim, ao promoverem o debate nos fóruns, também contribuíram com o exercício de escrita das cursistas que, por meio 


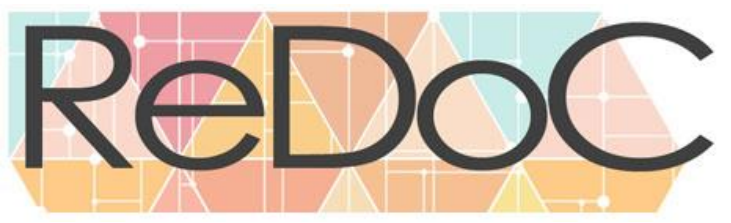

Revista Docência e Cibercultura

das videoaulas como objeto de análise, sintetizaram seus pensamentos e se dispuseram à interação com outras cursistas.

\section{Considerações Finais}

Como tecnologias acessórias, as videoaulas possibilitaram não apenas a exposição do pensamento das autoras, mas também, vistas em conjunto, a comparação entre diferentes perspectivas diante das lesbianidades. No decorrer do curso, com o uso das videoaulas, começamos a perceber que comparações entre as autoras foram sendo estabelecidas pelas cursistas e que preferências com relação a uma ou outra perspectivas se definiam nos fóruns de discussão. Nesse sentido, as videoaulas contribuíram com a ilustração do pensamento lésbico enquanto epistemologia feminista, ou seja, enquanto um continuum reflexivo sobre uma mesma questão. Além disso, consideramos que os diferentes conceitos apresentados puderam ser escrutinados na sua eficácia na compreensão do cotidiano lésbico, subjetivo, político ou profissional.

Consideramos que as videoaulas do curso Pensamento Lésbico Contemporâneo foram uma tecnologia fundamental para o acesso das cursistas ao pensamento das autoras, uma vez que funcionaram como instrumento de tradução cultural de um pensamento complexo para públicos com menor trânsito com o texto acadêmico. Ainda, por meio das videoaulas, mesmo aquelas que possuíam trânsito acadêmico, puderam mais facilmente comparar pensamentos e reflexões, avaliar conceitos e promover o debate menos individualizado no pensamento dessa ou daquela autora, possibilitando que a reflexão fosse epistemológica no sentido de compreensão de uma totalidade do pensamento lésbico a partir das singularidades de cada autora estudada.

\section{REFERÊNCIAS}

ANGELO, Cristiane Malinoski Pianaro; MENEGASSI, Renilson José. The writing production and the teacher's work in the support classroom. Alfa, São Paulo, v. 60, n. 3, p. 475-506, dez. 2016. Disponível em: http://www.scielo.br/scielo.php?script=sci_arttext\&pid=S198157942016000300475\&lng=en\&nrm=iso\&tlng=en. Acesso em: 22 mar. 2020. 
ARAÚJO, Júlio César; DIEB, Messias. Autoria e deontologia: mediação de princípios éticos e práticas de letramento na escrita acadêmica em um fórum virtual. RBLA, Belo Horizonte, v. 13, n. 1, p. 83-104, 1 jan. 2013. Disponível em: http://www.scielo.br/scielo.php?pid=S198463982012005000001\&script=sci_abstract\&tlng=pt. Acesso em 22 mar. 2020.

CASTELLS, Manuel. A Sociedade em Rede. 8. ed. v. 1. São Paulo: Paz \& Terra, 2000.

COSTA, Ana Alice et al. Uma conversa franca com MH/Sam Bourcier sobre correntes feministas e queer na contemporaneidade. Revista Feminismos, Salvador, v. 2, n. 2/3, p. 28 59, 2. 2015.2 Dem. 201 em: https://portalseer.ufba.br/index.php/feminismos/article/view/30143. Acesso em: 22 mar. 2020.

FALQUET, Jules. Romper o tabu da heterossexualidade: contribuições da lesbianidade como movimento social e teoria política. Cadernos de Crítica Feminista, Recife, ano VI, n. 5, p. 831, 2012. Disponível em: https://julesfalquet.files.wordpress.com/2010/05/art-port-romper-otabu-da-heterosexualidade.pdf. Acesso em: 22 mar. 2020.

FERNANDES, Felipe Bruno Martins; CARLOS, Paula Pinhal de. A Interdisciplinaridade nos Estudos de Gênero: análise das teses do Doutorado Interdisciplinar em Ciências Humanas da UFSC. Cadernos de Pesquisa Interdisciplinar em Ciências Humanas, Florianópolis, v. 10, n. 97, p.80-94, 1 dez. 2009. Disponível em: https://periodicos.ufsc.br/index.php/cadernosdepesquisa/article/view/1984-

9851.2009v10n97p80. Acesso em: 22 mar. 2020.

FERREIRA, Marília Mendes; LOUSADA, Eliane Gouvêa. Ações do Laboratório de Letramento Acadêmico da USP: promovendo a escrita acadêmica na graduação e na pósgraduação. Ilha do Desterro: A Journal Of English Language, Literatures in English and Cultural Studies, Florianópolis, v. 69, n. 3, p. 125-138, 27 set. 2016. Disponível em: http://www.scielo.br/scielo.php?script=sci_arttext\&pid=S2175-80262016000300125. Acesso em: 22 mar. 2020.

HERINGER, Rosana. Democratização da educação superior no Brasil: das metas de inclusão ao sucesso acadêmico. Revista Brasileira de Orientação Profissional, Porto Alegre, v. 19, n. 1, p.7-17, jun. $2018 . \quad$ Disponível https://www.redalyc.org/jatsRepo/2030/203058814003/203058814003.pdf. Acesso em: 22 mar. 2020.

LESBIANISMO como uma Ato de Resistência: o pensamento de Cheryl Clarke. Direção de Felipe Bruno Martins Fernandes. Intérprete: Giovanna Oliveira. Roteiro: Igor Leonardo de Santana Torres. Música: Always (DJ Quads). Salvador: Grupo de Estudos Feministas em Política e Educação, 2017. (4.23 min.), digital, son., color. Legendado. Série Pensamento Lésbico Contemporâneo. Disponível em: https://youtu.be/YeiRsdv_f9M. Acesso em: 22 mar. 2020. 
O NARRADOR no cinema - Ismail Xavier. 2017. 1 vídeo (7 min 40 s). Publicado pelo canal Revista Significação.

Disponível

em: <https://www.youtube.com/watch?v=bHBZ4RQQMZk>. Acesso em: 17 set. 2018.

PRETTO, Nelson De Luca. Uma escola sem/com futuro: educação e multimídia. 8. ed. Salvador: $\quad 2013.2$ Disponível em: https://repositorio.ufba.br/ri/bitstream/ri/15033/1/escola-sem-com-futuro_RI.pdf. Acesso em: 22 mar. 2020.

RICH, Adrienne. Heterossexualidade compulsória e existência lésbica. Bagoas, Natal, v. 4, n. 5, 27 nov. 2012. Disponível em: https://periodicos.ufrn.br/bagoas/article/view/2309. Acesso em: 22 mar. 2020.

ROCHA, Maria do Carmo Suzarte; RANGEL, Marcia Tereza Rebouças; SOUZA, Lanara Guimarães de. Introdução à Educação a Distância. Salvador: UFBA/ Superintendência de $\mathrm{EaD}$, $2017 . \quad$ Disponível em: https://educapes.capes.gov.br/bitstream/capes/174995/5/eBook_Introducao_a_EaD_UFBA.pd f. Acesso em: 22 mar. 2020.

SANTOS, Edméa. Salto para o Futuro: Tecnologias na Educação. 2016. Disponível em: $<$ https://

tvescola.org.br/tve/video;jsessionid=8B63086BD037E7749C6B9676505CF7B8?vlItem=salto -para-o-futuro-tecnologias-na-educacao\&>. Acesso em: 17 set. 2018.

SANTOS, Edméa. A cibercultura e a educação em tempos de mobilidade e redes sociais: conversando com os cotidianos. In: FONTOURA, Helena Amaral da; SILVA, Marco. Práticas Pedagógicas, Linguagem e Mídias: desafios à Pós-graduação em Educação em suas múltiplas dimensões. Rio de Janeiro: Anped Nacional, 2011. p. 75-98.

SALA de Cinema: Ismail Xavier. 2013. 1 vídeo (54 min 14 s). Publicado pelo canal SescTV. Disponível em: 〈https://www.youtube.com/watch?v=Zk9AON3og6c>. Acesso em: 17 set. 2018.

SOUSA, António Carlos Corte-real de; OLIVEIRA, Carlos Alberto Bragança de; BORGES, José Luís Cabral Moura. Utilização do sucesso acadêmico para prever o abandono escolar de estudantes do ensino superior: um caso de estudo. Educação e Pesquisa, Porto, v. 44, n. 1, p.119, nov. 2017. Disponível em: http://www.scielo.br/pdf/ep/v44/1517-9702-ep-44e180590.pdf. Acesso em: 22 mar. 2020.

USTÁRROZ, Elisa; QUADROS, Sérgio Feldmann de; MOROSINI, Marilia Costa. Democratização da Educação Superior Brasileira: do acesso ao compromisso com o sucesso acadêmico. Revista Internacional de Educação Superior, Campinas, v. 3, n. 3, p.539-561, dez. 2017. Disponível em: https://periodicos.sbu.unicamp.br/ojs/index.php/riesup/article/view/8650622/16835. Acesso em: 22 mar. 2020. 


\section{Agradecimentos}

Este texto é oriundo de meu Trabalho de Conclusão do Curso de Especialização em Produção de Mídias para a Educação On-line da Faculdade de Educação da Universidade Federal da Bahia (UFBA), como requisito parcial para a obtenção do grau de Especialista, defendido no segundo semestre de 2018. Agradeço a toda a equipe do curso, à coordenadora professora Lanara Guimarães de Souza. Também à minha tutora, que acompanhou meu crescimento durante todo o curso, professora Izabel Cristina Silva Xavier. Por fim, à minha orientadora professora Mônica de Sá Dantas Paz. Agradeço também ao apoio da Pró-Reitoria de Extensão da UFBA pelo apoio financeiro ao projeto Pensamento Lésbico Contemporâneo e a toda a equipe e cursistas que fizeram desse projeto uma possibilidade de inovação em gênero e sexualidades nos campos da extensão e da Educação a Distância. Um agradecimento especial à coordenadora dos movimentos sociais, Bárbara Alves, integrante do Coletivo Lesbibahia, parceiro na execução do projeto, e a Igor Leonardo Torres, que auxiliou na formatação do texto para publicação. Agradeço ainda a Alberto Escobar e a Tan Saunders, pela revisão dos resumos em segunda língua. 


\section{APÊNDICE A}

Trecho da Storyline de uma das videoulas do curso: Lesbianismo como um Ato de Resistência: o pensamento de Cheryl Clarke (LESBIANISMO, 2017).

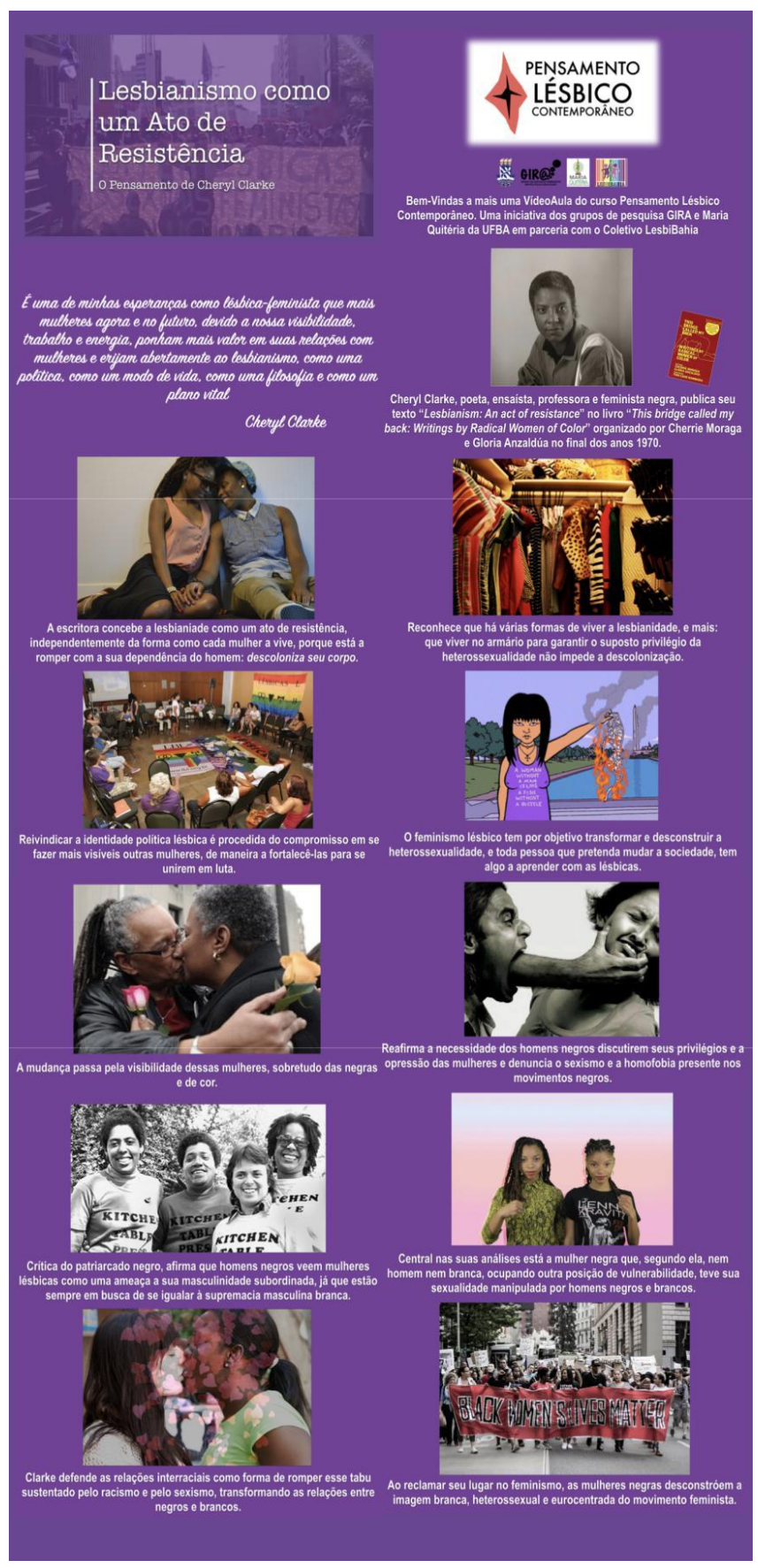

Fonte: Elaboração própria. 